\title{
Creating Localized Resilient Places in Community -Thoughts on Renovation Practice of Wuhan Farmers' Market after the Covid-19 Pandemic
}

Fei Dong, Wuhan Planning and Design Institute, China

Qing Li, Wuhan Planning and Design Institute, China

Kun Wu, Wuhan Planning and Design Institute, China

\begin{abstract}
Traditional wet farmer's market is an important component of urban life. During the pandemic, a Wuhan farmers' Market where affected groups came to the fore was pushed to the cusp. With a renovation action of farmer's markets in Wuhan, farmer's markets are placed in the context of surrounding communities and urban systems in thinking about their positions and responsibilities. Meanwhile the paper study the further directions and strategies of renovation of traditional farmer's markets in post-pandemic era. The work is mainly divided into three parts. Firstly, by summarizing the features of farmer's markets, the paper discusses the explicit and implicit function characteristics of farmer's markets in different types of communities. Secondly, comparing to functional changes and characteristics of gathered population before and during the pandemic, it is proposed that the market is can be explored as available resources in refuge and disaster prevention system during the pandemic or other disasters. Thirdly, the paper proposes that the main principle of the new round of renovation of farmers' market is 'peacetime and wartime combination' to enhance the resilience of city facilities and infrastructures.
\end{abstract}

\section{Keywords}

Farmer's market; environmental protection; resilient city; community center

As an important component of urban life in China and the whole Asia, traditional wet(fresh) farmer's market is not only a place for daily consumptions of urban residents, but also the community vitality center. Various small restaurants and small department stores gather around traditional markets, forming a 'street market' area. With the development of economy, the consumption pattern has been transformed from the monopoly of going to traditional farmers' market to diverse ways of shopping, such as supermarkets, chain stores and E-commerce delivery services. The emerging consumption patterns have profoundly influenced contemporary China. However, a large number of citizens are keen on selecting satisfactory goods in a farmers' market. Relying on the strong user adhesiveness of farmers' market and the traditional commercial customs of $s$ treet markets in Asian cities, food related industries such as breakfast restaurants, food processing stores, seasoning stores and community level service industries such as barbershops, laundries and infant stores, are continuously gathering along the streets around farmer's markets. Community-rooted traditional farmer's market has strong vitality and irreplaceability.

During the pandemic, the Wuhan wet(fresh) farmers' market where affected population came to the fore was pushed to the cusp. Related issues like environmental pollution, lagging supporting facilities and traffic jam were controversial. Shutting down the market is just a temporary solution. As the micro center of basic livelihood and city life, the market played an irreplaceable role even during the lockdown period. 
This is also a reminder for urban planning professionals to pay attention to community public placemaking so as to enhance city resilience.

\section{Explicit and implicit characteristics of farmer's markets}

\subsection{Community center and significant public space}

In old cities with limited space and insufficient open spaces, farmer's markets are generally located in the community center, covering the surrounding 1-3 square kilometers. The service radius of a farmer's market in a city's new district area where public service facilities are relatively lagging also reaches to 2000 meters (Figure 1).

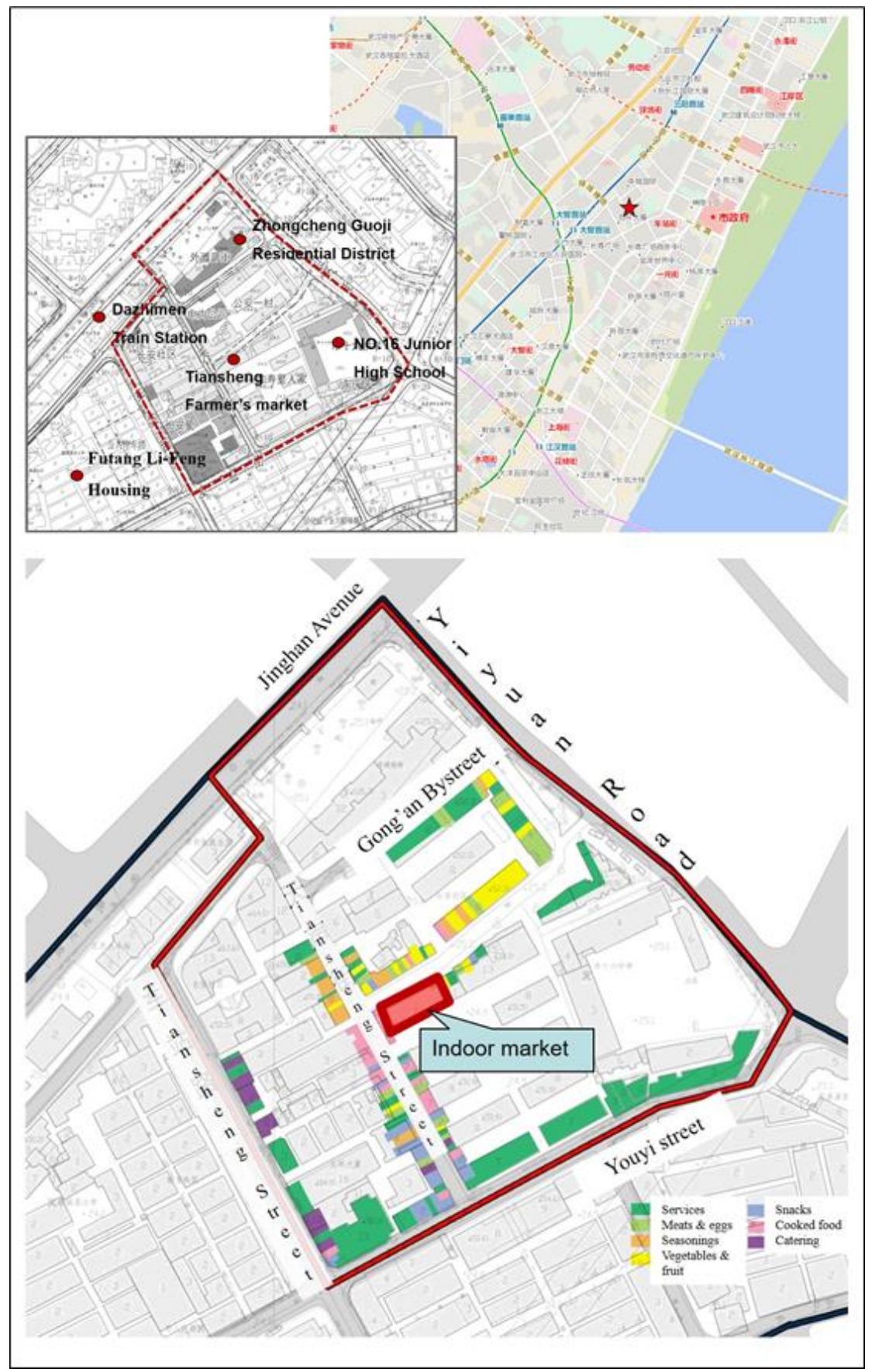

Figure 1. Layout for Current Situation of Farmer's Markets in Wuhan. Source: Plotted by Authors. 
A wet(fresh) farmer's market includes various formats such as fresh ingredients, seasonings, cooked food and life service and accurately matches the living demands of surrounding communities. Community residents can frequently interact with neighbours when consuming, buying and enjoying services in the market. Farmer's markets not only meet residents' daily living demands, but also gradually evolve into important community centers and public communication space.

We take Tiansheng Community in the old city of Hankou for a research example. The 8.5 hectares area of Tiansheng Community is located at the intersection of urban development area and historical district. Tiansheng Farmer's Market, covering an area of $800 \mathrm{~m}^{2}$ was built in the $1980 \mathrm{~s}$, but today, in Tiansheng Farmer's Market area, a huge number of stores are opening along the areas' three streets, where neighbours and eaters shuttle among them. Through analyses on big data and people's activity diagram (Figure 2), it can be found that Tiansheng Farmer's Market has the most visitors within the area of 3-4 hectares with its own smash hit commodities. More than ten types of deli foods in Tiansheng Market are known far and wide, such as fish rice noodle, Wuhan hot dry noodles, preserved vegetable \& pork dish , among which several are on the best food lists of various media and become an Internet-famous site for many local and non-local foodies to come from afar.

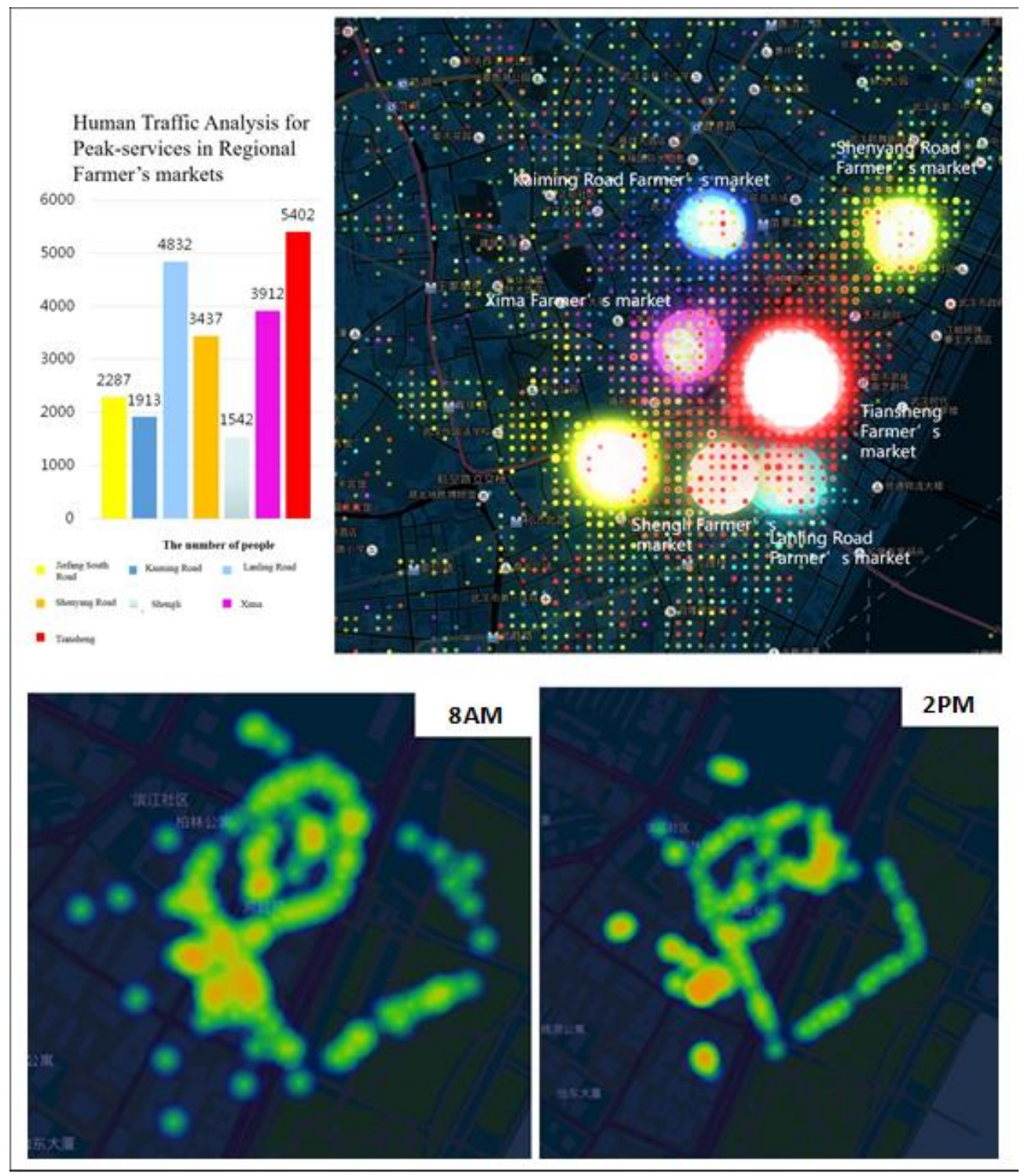

Figure 2. Human Traffic Analysis Around Research Area. Source: Plotted by Authors. 


\subsection{Providing job opportunities and relieving the pressure of population aging}

Diversified small businesses in the street markets provide massive job opportunities for local residents and non-locals. The increased employment rate will correspondingly decrease social issues related to poverty, welfare dependence and family disputes. Meanwhile, a stable flow-in of non-locals can effectively alleviate population aging in the old city.

Tiansheng Community possesses a total population of 9,731. Statistical data as of 2017 show that proportion of the aging population reaches $20 \%$ and the proportion of floating population (lessee) reaches up to $35 \%$. (Figure 3) Floating population mainly include young adults, migrant workers and market vendors who mainly work and live in Tiansheng Farmers' Market.

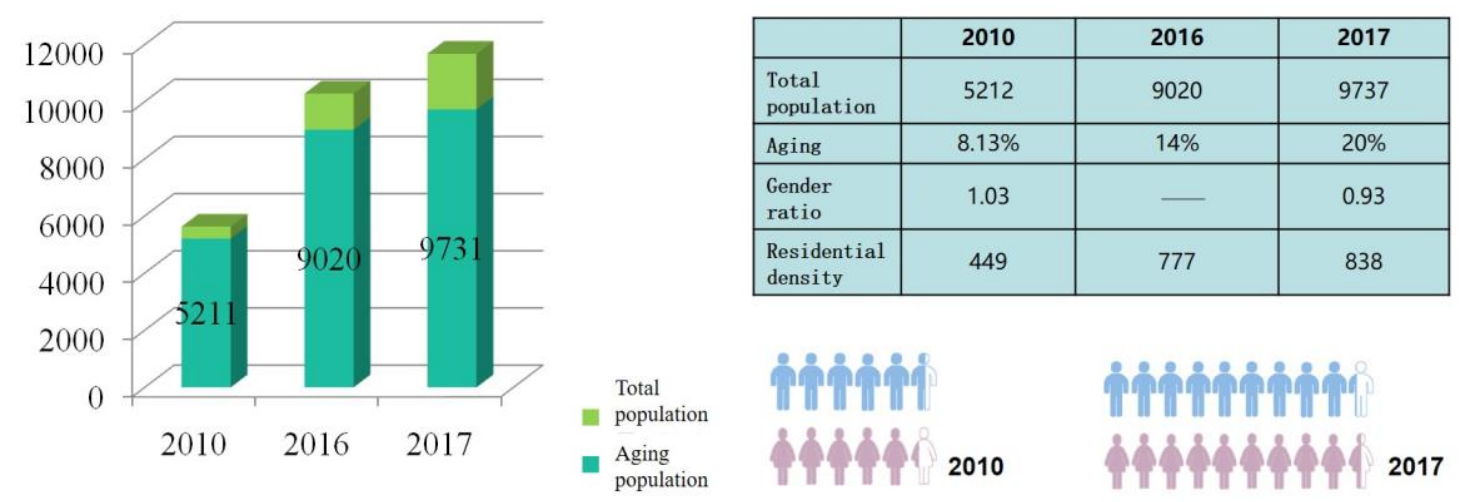

Figure 3. Tiansheng Community Demographic Statistics. Source: Wuhan Public Security Bureau.

\subsection{Demonstrating local characteristics and emerging tourist attractions}

The real city spirit is to maintain the vitality of people which is the lifeblood of a city. City characteristics are not only reflected in physical spaces such as streets and buildings, but also reflected in unique and irreplaceable cities and communities embedded in lifestyle of locals. Farmer's markets have integrated into our daily life and vitality, neighbourhood relationship and old way of life carried by it represent the 'collective memory' which locals and non-locals continuously accumulates generation after generation and 'homesickness' in a cultural sense. More and more farmers' markets become the emerging Internetfamous tourism sites as they satisfying tourists' deep experience demands towards local life and city views for reflecting local people and their daily lives (Figure 4).

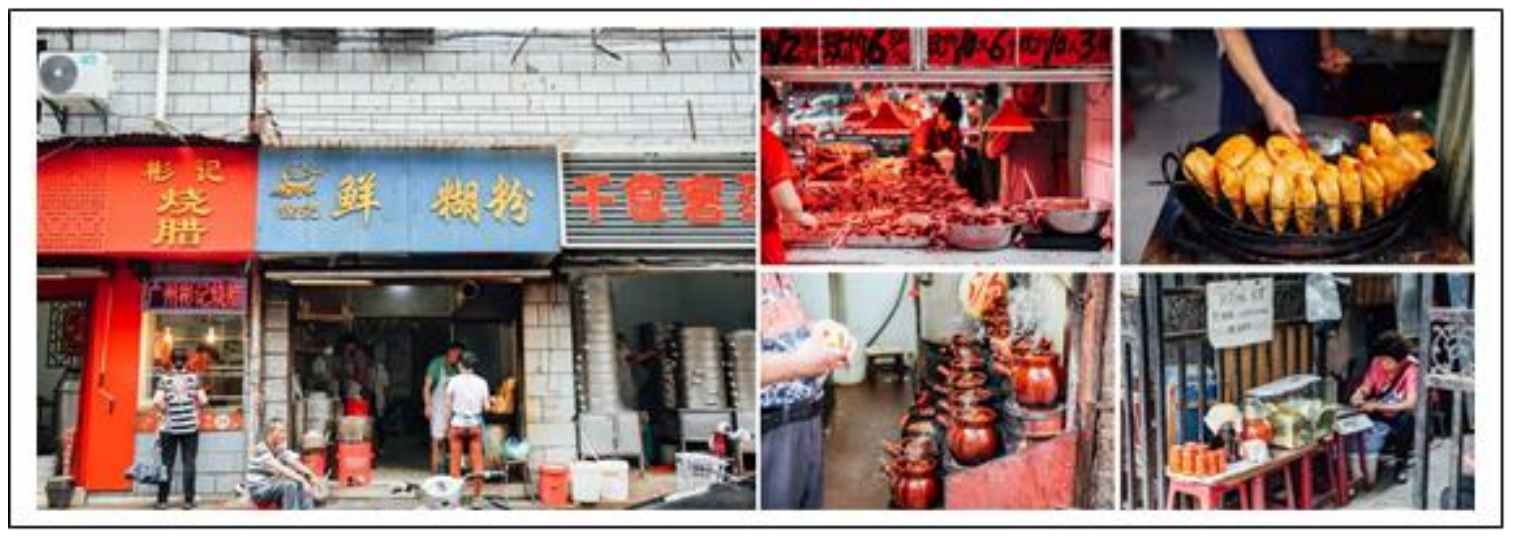

Figure 4. Traditional Food Restaurants and Stalls in Tiansheng Community. Source: Taken by Authors. 


\section{The Evolution of farmers' market}

\subsection{The Process of Renovation before the Covid19 Pandemic}

'Grocery basket' is a major issue concerning the people's livelihood. Since the establishment of PR China, farmer's markets in Wuhan City have been continuously improved in layout, construction and operation management after successive development process of 'Unitary Government Running -Free Marketization-Renovation'.

During Planned Economy Era of China, Wuhan Government uniformly purchased and sold vegetables. Private vegetable industries were gradually transformed to state/government-operated farmer's markets. In 1984, Wuhan firstly opened farmers' free markets in the whole country, where suburban farmers gathered outside the state-operated markets with their agricultural products, spontaneously forming a semi-outdoor street market. The free market then became an important circulation place in the context of market economy but gradually became a 'black spot' of environment and security in urban central area. After repeated reorganizations and renovations, outdoor stalls were basically replaced and farmers' market street blocks with formal operation licenses have been formed. Urban industrial and commercial units with special operation became the operators instead of farmers, but we still call them as 'Farmers' Market'.

After entering the century of 2000, Wuhan has strengthened the construction and renovation of farmer's markets. In 2002, the municipal government proposed the project of 'transforming farmer's market into supermarkets' and planned to create a model of 'farmers' market+ supermarkets' in order to change the 'dirty, disorderly and bad environment' images and 'inaccurate scale' issue of farmer's markets. In 2013, in order to reach the standards of the 'national civilized city, national sanitary city and national model city for environmental protection', Wuhan Municipal Government carried out a renovation action of farmer's markets and invested in 200 million yuan to improve infrastructure and sanitary conditions of 285 farmers' markets in the whole city in all aspects. In 2014, led by the Municipal Bureau of Commerce, Municipal Bureau for Urban Planning cooperated in preparation of 'Spatial Layout Planning of Standardized Farmer's markets in Wuhan (2014-2020)' implementing 6 renovation and construction standards of standardized farmer's markets (WNRPB, 2015).

After continuous renovations and constructions, the environment of farmer's markets in Wuhan has been significantly improved, but low operation management level, environment, outdated operating modes and other issues of farmer's markets have also been the focus of urban management. With the aim to implement opinions of the 19th National Congress of the Communist Party of China on forming a pattern of green development, reducing domestic waste from the source, and improving resource reutilization rate, Wuhan Urban Management Enforcement Committee organized the preparation of Technical Guidelines for Nearby Treatment of Wet Garbage in Wuhan (Trial) in 2019. Meanwhile, it started to promote nearby resource utilization pilot which was firstly carried out in residence communities, garbage transfer stations, farmers' market and fruit \& farmer's markets where rain and sewage water were diverted.

Huanan Seafood Wholesale Market became the target of public criticism after the outbreak of the pandemic in 2020. It is extremely urgent to improve environmental health of farmer' market and strengthen market management level. Under the multiple background, Wuhan set off a wave of farmers' markets renovation after the pandemic lockdown. The city renovated all farmers' markets in a standardized way in the whole city to promote its transformation and development, adapt to new industry development trends and comply with the changes of consumers' updated demand. 


\subsection{A new round of renovation after the pandemic}

Priorities of the renovation of Wuhan Farmers' Markets in 2020 are mainly in implementing environmentally friendly facilities, smart equipment and integrated services (WMBMS, 2020). The renovated farmers' markets are divided into three levels based current condition and how the workings will be done.

Reduction of market garbage from the source, resource utilization and sewage treatment are the main aims in the new round of renovation. All first-level markets should be equipped with garbage classification and collection room, wet garbage disposal room, nearby biochemical treatment equipment and all other facilities as required, which can be used to dispose wet garbage and food waste in both farmer's markets and surrounding residential areas. Reduction of garbage from the source and environmentally friendly sewage disposal can effectively reduce cleaning and transportation expenses of wet garbage and dramatically decrease the secondary pollution risks during transportation, thusly improve urban environment and overall increase reduction, recycling and harmless disposal level of domestic garbage in Wuhan with a better disease prevention ability.

Second-level markets are additionally provided with smart management system on the basis of hardware upgradation, emphasizing on 'smart operation'. Smart management system of farmer's market includes pesticide residue testing and food tracking. Mobile APP and Internet of Things equipment are used for data collection and uploading related invoice and tickets with just one click. Data on purchase ledger, ticket information, food testing, transaction detail and other contents of market merchants can be stored to form information database in each link of market. Information screen hung in the front of stall should show business license, name, contact mode, health certificate and other information of merchants. Price and weight of vegetable can be shown on display after vegetables are put on the scale, which realizes 'scale and screen interconnection'.

At bottom, hardware transformation and software upgrading all concentrate on operation functions of a farmer's market in a narrow sense. Third-level markets enable traditional farmer's markets from culture, service and other aspects to facilitate their 'going out of bounds'. Personized decoration style makes many farmer's markets popular Internet-famous sites. The 'Mingchengyipin' market is decorated in an nostalgia style. Store signage are designed with the Twenty-Four Solar Terms texts, photo wall showing famous landmarks such as Minzhu Road, Hubu Lane, Han River, Yangtze River, Jianghan Road, Yellow Crane Tower, Yangtze River Bridge, black and white television, spareribs and lotus root soup stewed with coal furnace......traditional history culture and elements with Wuhan local style can be seen everywhere. Taking Community Neighbourhood Centre as the main service, Shuiguo Lake Farmer's market which is called as one of 'the most beautiful farmer's markets in China' have been additionally equipped with children's playground, snack bar, breakfast bar, barber's shop, laundry, beauty and skin care shop, sharing kitchen and public display cabinet. The market can provide a complete range of services covering diets and daily home-based services and is synchronously equipped with charger, printer and other convenient service facilities, Integrating wisdom, convenience and public welfare, the market meets upgrade demands of comprehensive social contact, culture and shopping.

\section{Thoughts triggered by the pandemic}

In January 2020, the pandemic broke out in Wuhan. In order to control virus diffusion, the government of China adopted the strictest prevention and control strategy-lockdown, during which traffic, community and public places were closed, production and school were suspended. Wuhan had lockdown until the beginning of April 2020. How to guarantee the basic life of tens of millions of urban residents under the state of 'lockdown' brought great challenge to the government at the time of trying to save patients. 
Therefore, reflection and discussion on the pandemic should not be limited to special field of medical health, the people's livelihoods in communities should be brought to the attention.

After the pandemic, the planning professionals made a heated debate aimed at corresponding strategies planned under the context of the pandemic, future city development and other issues, during which healthy community and resilient city are frequently mentioned. No matter whether it is infrastructure resilience, system resilience, social resilience concept mentioned in resilient city theory, or physical health, mental health and social health involved in healthy community (Huang,2020), the planning professionals have gradually reached a consensus that improving urban public facilities and social governance level is indispensable for resisting urban disaster risk.

\subsection{Construction of resilient cities}

Disaster risks including natural disasters, significant social impact (such as war) and health emergency (such as pandemic) events are what modern cities face. 'Resilient City' refers to a city that has ability to conquer disasters, reduce losses from disasters, and reasonably allocate resources to quickly recover from disasters. Resilience of city has become one of core arguments of urban sustainable development, which is to effectively cope with various changes or impacts and minimize uncertainty \& vulnerability in development. It is normally believed that Resilient City has five main characteristics: robustness, recoverability, redundancy, intelligence and adaptability, as well as four dimensions, namely technology, organization, society, and economy.

Practice of Resilient City's redundancy and intelligence is particularly important for public health disasters like pandemic, where Shelter Hospitals have played a significant role. Public facilities with large space and capacity like stadiums and exhibition centers have been used for 'Standby Modules' on the occasion when medical resources are in short supply and normal medical facilities cannot fully exert its functionality. Investment in medical infrastructure construction in Wuhan has been increased after the pandemic, but it was difficult to keep such investment in construction of community-level public facilities for long. As a result, it is more pragmatic and effective to focus on 'Peacetime and Wartime Combination' in new construction, renovation and expansion projects of public facilities.

\subsection{Multi-subject co-governance}

Resilient City has a complex giant system of which the operation may not only be managed and maintained by government. Its operation will also need exact understanding of relationship between government, market, grass-roots level, society and culture, and need to construct multi-subject cogovernance system (Yin, 2020). To experts' view, the government plays a leading role, while the market plays a main role. The best interface between government and market is at grass-roots level, which is not only the place where potential risks arise, but also the place where cost of governance can be minimized. If $90 \%$ of risk prevention and control work of a city can be completed by market and society at grass-roots level, this will be the most important proof for governance capacity modernization (Sun, 2020).

Community is fundamental unit of urban operation and governance, and primary protection against pandemic. City grassroots governance and community residents' life will face two challenges, massive public affairs types and huge volume of them under major public health events similar to pandemic. To deal with massive demands from thousands of families are time-consuming and costing. The small sized grass-roots organizations cannot exhaustively deal with every of them. This is one of those important reasons why grass-roots community organizations in Wuhan failed to have a quick response which exactly embodied the flaw of organization level in current resilient city building.

Community establishment is an effective means to make 'Strangers Become Acquaintance', of which the core is to restore amiable relationship between people through frequent community events, such as community garden, community forum, community farm, etc., establishing a stable and close community 
relationship. Residents' spontaneous group establishment has played a vital role in final victory of pandemic war in Wuhan in addition to decisive factor of 'National System'. Residents set up various community groups, neighbourhood groups and small business groups to carry out group buying, mutual assistance and other activities to seek material support and obtain spiritual comfort, especially in lockdown stage of community. Countless small problems and emotions have been eliminated at the beginning, which greatly reduced work pressure of community staff. It can be concluded that establishing group is a kind of unintended and spontaneous community establishment. Experience in Wuhan has fully proved that community establishment can effectively improve resilience of community organizations.

\section{Thoughts on farmer's market renovation in post-pandemic period}

Farmer's market serves as an important community livelihood facility, and it construction shall not be limited to wet market, but also anything the surrounding community or even the whole city may need, where organizers shall think carefully its positioning, responsibility, and development plan. Focus and direction of upgrading and construction of farmer's market in post-pandemic era can be explored by new focus points from resilient cities, community establishment, environmental protection and pollution control.

\subsection{Improvement of Resilient City facilities}

Resilient Cities shall learn from past disasters and accidents to enhance adaptability to new ones. From perspective of Resilient City, various community-level public welfare facilities with small volume and wide coverage, including farmers' market, shall be regarded as important available resources in urban refuge and disaster prevention system. Principle of 'Peacetime and Wartime Combination' shall be treated as core in construction and operation. Construction guidance shall be proposed to increase design of 'Redundant' standby modules, with possibility for conversion.

Community farmers' market is generally about 1,000 square meters, with convenient transportation, and large service range. In Resilient City planning, market buildings may be regarded as community-level fresh food transfer unit, meanwhile as resilient facility modules, and providing emergency functions and resource reserves such as material storage and refrigeration, preliminary waste treatment in 'Peacetime and Wartime Combination'. Efficiency of material distribution during the War against Pandemic will be greatly improved as long as community residents and staff are very familiar with location, layout and round-trip transportation of community farmers' market, that panic and anxiety of community may be lowered effectively.

Taking Tiansheng Farmer's market as an example, although as a first level market, it is planned to build new centralized storage and freezing space in fresh food store area on the first floor, while reserving public entertainment area on the second floor, and perfecting basic facilities such as water, electricity and public toilets, and reserving superior command module interface in intelligent management system. During the basis of Tiansheng Farmer's market's daily operation, 'Peacetime and Wartime Combination' can sometimes have an 'Instantly Switch' into Tiansheng Community Fresh Material Distribution Center. The first floor is for storage and distribution of meat, poultry, eggs, aquatic products, vegetables and other materials, and the second floor is for temporary command office or an detached house,etc.

\subsection{Providing community establishment and platforms}

Community establishment and multi-subject co-governance to a Resilient City is of great significance as discussed above. Farmer's market normally has a characteristic of communication that is suitable for community establishment activities. Learning from renovation implementations in advanced cities like Shanghai, in new round of farmer's market renovation in Wuhan, it was expanded and increased multifunctional composite business elements such as catering, leisure and entertainment and community

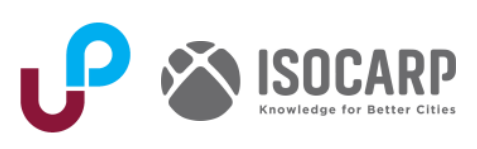


service in terms of conventional fresh food sales function (Zhan and Kong, 2020). However, expansion only involved operational functions. Experience in Singapore and Suzhou shall be learnt from in old farmer's markets with limited space, where community establishment shall be furnished with enough space for community activities besides taking care of commercial service expansion (Hangzhou Beinuo Market Research Centre, 2020). A neighbourhood center would integrate shopping, social communication, and activities (Figure 5).

Some areas on the second floor of wet market are planned to be used as public welfare community entertainment places in renovation project of Tiansheng Farmer's market, with a series of community activities and events. 'Vegetable Knowledge Market' teaching children to identify things like Rice, wheat, soybean, corn, \& potato, 'Food History Market' telling everyone grand navigation history with various spices, and 'Cook Training Market' providing a platform for everyone to exchange cooking experiences, and so on can upgrade farmer's market into 'Food Knowledge / History / Training Markets (and the like)' with unlimited possibilities, where social, cultural and community characteristics will be strengthened, and 'Gone Guests' such as children and youth will be attracted back, constantly enhancing social resilience of city. Communication and connection will be promoted in 'Normal Time', and there will be team-fighting for crisis in 'Peacetime and Wartime Combination'. 

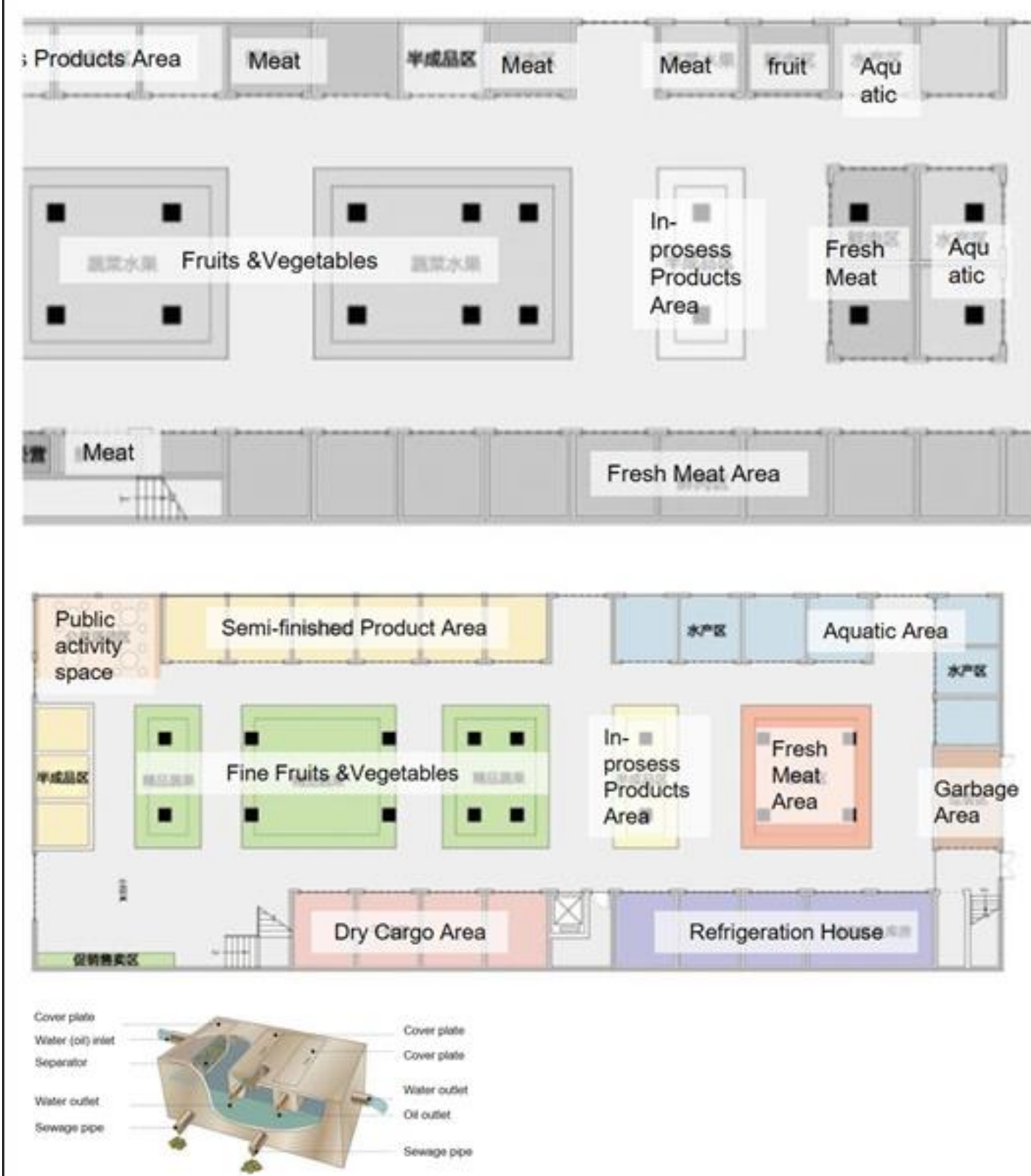

Oil separator

schematic diagram

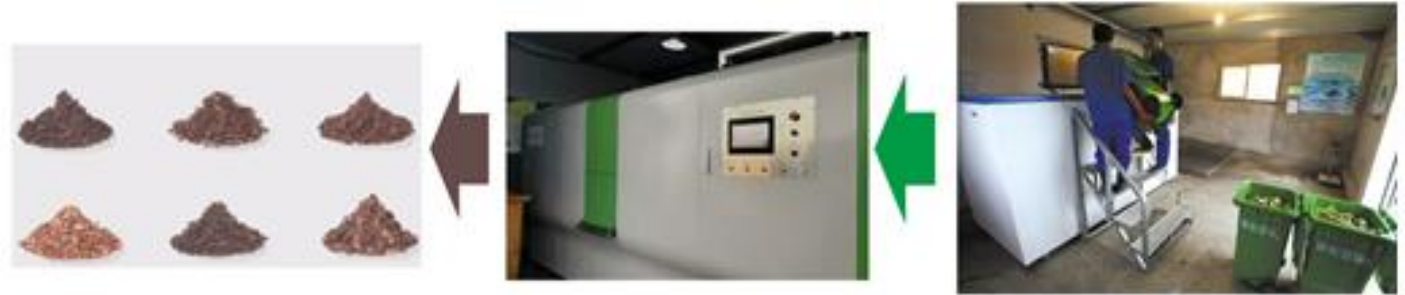

Figure 5. Renovated Farmers' Market 3.0. Source: Plotted by Authors. 


\subsection{Promotion of regional environmental protection upgrading}

State-organized farmers' markets have been the central target in current round of Wuhan's Farmers' Market Renovation Plan. In fact, surrounding small and micro service industries and mobile vendors are severely troubled by garbage and sewage. Many kitchens of traditional chophouses and historical restaurants along street around Tiansheng Farmer's market are directly connected to urban sewage pipework for oily water, bringing great pressure to environmental protection.

Upon upgrading of farmers' market environmental protection, the Renovation Plan puts forward corresponding requirements for surrounding restaurants and shops. Oil separation equipment shall be installed to chophouses along street to pre-process kitchen oil, reduce contamination before entering into sewage, reduce blockage of pipeline caused by oil floating debris, reduce maintenance cost of pipe network, and reduce treatment burden of sewage treatment plant (COD removal capacity of oil separation tank generally exceeds 40\%). Oil separation equipment shall be flexibly installed, disassembled and managed together with business license, which can effectively ensure implementation, and is ideal for chophouses with great mobility.

\section{References}

Hangzhou Beinuo Market Research Center. (2020) Sohu. Available at: https://www.sohu.com/na/419795966_120143556 (Accessed: 11 August 2021).

Huang, BL. et al. (2020) Tencent. Available at: https://mp.weixin.qq.com/s/fD6jN2JErTW23dGuRylchg (Accessed: 11 August 2021)

Sun, JP. (2020) Tencent. Available at: https://new.qq.com/rain/a/20201213A01H1300 (Accessed: 10 July 2021)

Yin, Z. (2020) Sohu. Available at: https://www.sohu.com/a/385246740_120179484 (Accessed: 5 July 2021)

Wuhan Municipal Bureau of Market Supervision. (2020) 'Standardized Renovation Implementing Plan of Wuhan Farmers' Markets(Vegetable Markets) ' Explanation Report. Available at: http://www.wuhan.gov.cn/zwgk/xxgk/zcjd/202005/t20200526_1335085.shtml (Accessed: 1 June 2021).

Wuhan Natural Resources and Planning Bureau. (2015) Spatial Layout Planning of Standardized Farmer's markets in Wuhan (2014-2020). Available at: http://zrzyhgh.wuhan.gov.cn/zwgk_18/fdzdgk/ghjh/zzqgh/202001/t20200107_602794.shtml (Accessed: 8 June 2021 )

Zhai, GF. (2016) Urban Public Safety Planning. Beijing: China Architecture \& Building Press

Zhan,Y. and Kong, MX.(2020) Tencent. Available at: https://new.qq.com/omn/20200529/20200529A0RWLL00.html (Accessed: 5 July 2021). 